\title{
Creep Tests AND Microstructure ANALYSIS OF THE SUPERHEATER
}

\author{
ZBYNEK BUNDA, JOSEF VOLÁK, JOSEF MACH, \\ MARTIN STEPANEK \& VACLAV MENTL
}

Abstract: Assessment of remaining lifetime represents a very complicated problem, which needs the knowledge of degradation processes in the material of a component, and also the service conditions of the components, e.g. way of loading and the influence of the surrounding environment. There is a common interest to operate the produced components as effectively as possible and thus as long as possible without reducing their safety and reliability, what could cause economic and human losses. This is a problem of safe operation and its prolongation in justifiable cases. As a result of new modern and more resistant materials development, the general interest is to be able to evaluate the extent and rate of degradation processes at various service conditions, mainly to prevent the components from brittle fracture. At present, the assessment of component material microstructure is one of the methods that makes it possible to evaluate its remaining lifetime. It is thus important to be able to evaluate the extent of material mechanical properties degradation as a result of various service factors and the elaboration of methods for its assessment. Nowadays, the evaluation of component material microstructure represents one of the possible methods for remaining lifetime assessment.

Key words: Superheater; Microstructure; Creep test; Residual lifetime
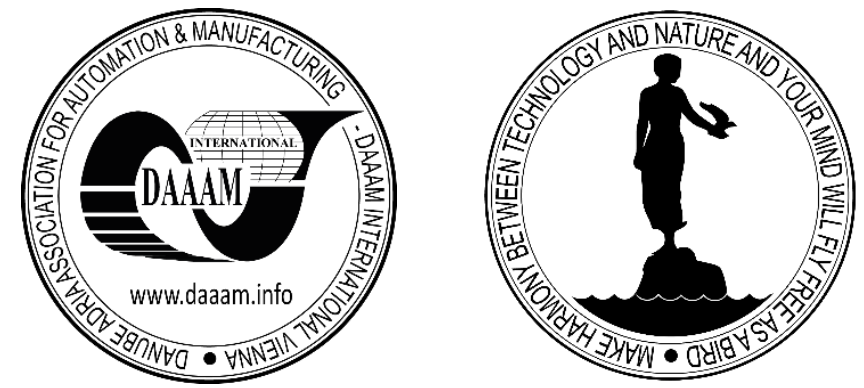

Authors' data: Zbynek Bunda, Josef Volák, Josef Mach, Martin Stepanek \& Vaclav Mentl, University of West Bohemia in Pilsen, RTI, Univerzitní 8, 30100 Pilsen, CZ, bunda@rti.zcu.cz

This Publication has to be referred as: Bunda, Z[bynek]; Volak, J[osef]; Mach, J[osef]; Stepanek, M[artin] \& Mentl, V[aclav] (2020). Creep Tests and Microstructure Analysis of the Superheater, Chapter 23 in DAAAM International Scientific Book 2020, pp.259-266, B. Katalinic (Ed.), Published by DAAAM International, ISBN 9783-902734-27-3, ISSN 1726-9687, Vienna, Austria

DOI: $10.2507 /$ daaam.scibook.2020.23 
Bunda, Z.; Volak, J.; Mach, J.; Stepanek, M. \& Mentl, V.: Creep Tests and Microstr...

\section{Introduction}

The article deals with the evaluation of the remaining lifetime on the basis of microstructure evaluation of selected materials in the power producing industry. At first, the microstructure investigation of selected component, where the customer's demand was to assess the remaining lifetime by means of traditional creep tests. On the basis of performed creep tests the remaining lifetime was determined by usual procedure. After finishing the creep tests the microstructure was investigated again. The evaluation of the creep tests and comparison of the microstructure before and after the tests is in detail summarized in this article.

\section{Creep tests}

The main principle of a creep test is heating of a testing pole to the pre-defined temperature and loading of the testing pole by tension force in a direction of the longitudinal axis of the pole. The following standards are valid for creep tests at higher temperatures: ČSN EN 10 291-6/2001, DIN 50118 and ASTME 139. The tests are performed on special testing devices that are called ,stands“.

Evaluation of creep test results - especially stress rupture strength RmT and creep strength RT - are based on a large number of tests. It can be determined for the following periods of time: $103 \mathrm{~h}, 5 \times 103 \mathrm{~h}$ or $105 \mathrm{~h}$ (it means that the time duration of a test is more than 10 years). While verifying properties of a new kind of steel up to 30 testing poles need to be evaluated. Total time duration of those tests is approximately (1-3) x $105 \mathrm{~h}$, however, time duration of some testing poles must be more than $104 \mathrm{~h}$.

\subsection{Time extrapolation of creep test results}

Time extrapolation of results is performed during creep tests. One of the most frequently used methods of interpolation is a method that makes use of Larson-Miller parameter. This extrapolation is based on Arrhenian relation, therefore it is possible to mutually substitute influence of temperature and time during the process. The following relation (1) is valid for the Larson-Miller parameter P [9]:

$$
P=T_{1} \cdot\left(C+\log t_{1}\right)=T_{2} \cdot\left(C+\log t_{2}\right)
$$

It means that effect of temperature $\mathrm{T} 1$ during test time $\mathrm{t} 1$ is equivalent to the effect of temperature T2 during test time $\mathrm{t} 2$. Process at a temperature T1 and a very long time $\mathrm{t} 1 \mathrm{can}$ be substituted by a process much shorter but at a higher temperature [1]. Another possibility is a combination of increase or decrease of stress at the same temperature. The following table and graph summarize results of creep tests that were performed on the material SA 213-T22 [2].

\begin{tabular}{|c|c|c|c|c|}
\hline Locality & $\begin{array}{c}\text { Temperature T } \\
{\left[{ }^{\circ} \mathbf{C}\right]}\end{array}$ & $\begin{array}{c}\text { Stress } \\
{[\mathbf{M P a}]}\end{array}$ & $\begin{array}{c}\text { Time to rupture } \\
{[\mathbf{h}]}\end{array}$ & $\begin{array}{c}\text { Parameter Larson - } \\
\text { Miller }\left[\mathbf{P L M}_{\text {LM }}\right]\end{array}$ \\
\hline Superheater 1 & 580 & 75 & 1965 & 19873 \\
\hline
\end{tabular}




\begin{tabular}{|c|c|c|c|c|}
\hline & & 80 & 890 & 19579 \\
\hline & & 100 & 185 & 18997 \\
\hline & & 120 & 50 & 18512 \\
\hline & & 140 & 7 & 17784 \\
\hline \multirow{5}{*}{ Superheater 2} & \multirow{5}{*}{580} & 75 & 1841 & 19849 \\
\hline & & 80 & 681 & 19480 \\
\hline & & 100 & 148 & 18915 \\
\hline & & 120 & 51 & 18520 \\
\hline & & 140 & 9 & 17877 \\
\hline \multirow{5}{*}{ Superheater 3} & \multirow{5}{*}{580} & 75 & 1507 & 19774 \\
\hline & & 80 & 792 & 19536 \\
\hline & & 100 & 206,5 & 19038 \\
\hline & & 120 & 50 & 18512 \\
\hline & & 140 & 15 & 18066 \\
\hline
\end{tabular}

Tab. 1. Results of creep tests - steel SA $213-$ T22.

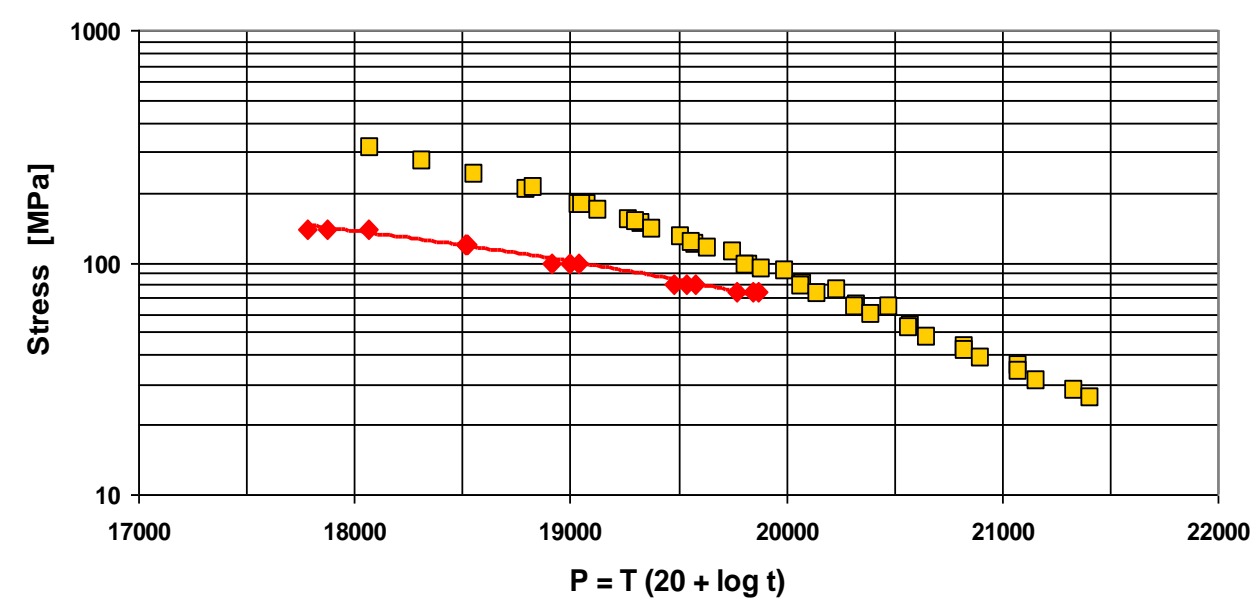

Fig. 1. Results of creep tests, steel SA 213 - T22.

Larson-Miller parameter (3) for superheater is (2).

$$
\begin{aligned}
& P_{L M}=19990 \\
& P_{L M}=T \cdot\left(20+\log \tau_{\text {rboiler }}\right)
\end{aligned}
$$

Residual lifetime of the boiler steam piping for temperature $539^{\circ} \mathrm{C}$ is in (4):

$$
\tau_{\text {rboiler }}=10^{\left(\frac{P}{T}-20\right)}=10^{\left(\frac{19990}{539+273,15}-20\right)} \cong 41085[h]
$$

\section{Microstructure analysis}


Bunda, Z.; Volak, J.; Mach, J.; Stepanek, M. \& Mentl, V.: Creep Tests and Microstr...

There are several methods to examine the quality and condition of materials and joints at the stage of new pressure equipment manufacturing as well as during the operational lifetime of any industrial pressure equipment [3]. Reliability of power plant components depends also on preventing material defects, which is closely linked to the estimation of the residual lifetime of power equipment. Verification of microstructural status can significantly contribute to this purpose. This verification can be done in two ways - using nondestructive investigation of microstructure or traditionally by sampling. The aim is to find out real status of power plant parts and essentially contribute to the estimation of residual lifetime in power plant parts.

The goal was to evaluate the microstructure of the inspected power plant components and to classify the material status according to the microstructure degradation standard scales, which were set up using real micrographs.

The samples before and after the creep tests were chosen for the evaluation. The samples were etched in the etching agent Nital. Microstructure analysis was carried out by an optical microscope Nikon Epiphot 300. Pictures of the fracture areas were taken by an electron microscope but because of the heavy oxidation of the crack surfaces it was impossible to get any qualitative characteristics.

The analysis was primarily focused on type, shape and size of structure formations, volume and distribution of the phases present and character of imperfections. The purpose of the metallographic analysis and evaluation was to determine grade of the material degradation. Instead of cutting off a part of power plants components, it is also possible to use nondestructive Replica - technique $[4,5,6]$ which is used especially directly in power plants. The microstructures of the investigated samples were evaluated according to two scales. The first one was the scale of the microstructure changes due to the long-term effect of high temperature which contains five (1-5) grades of damage and the second one was the scale for evaluation of the material degradation due to the cavitation damage which includes six (I-VI) grades [2], [7], [8], [9].

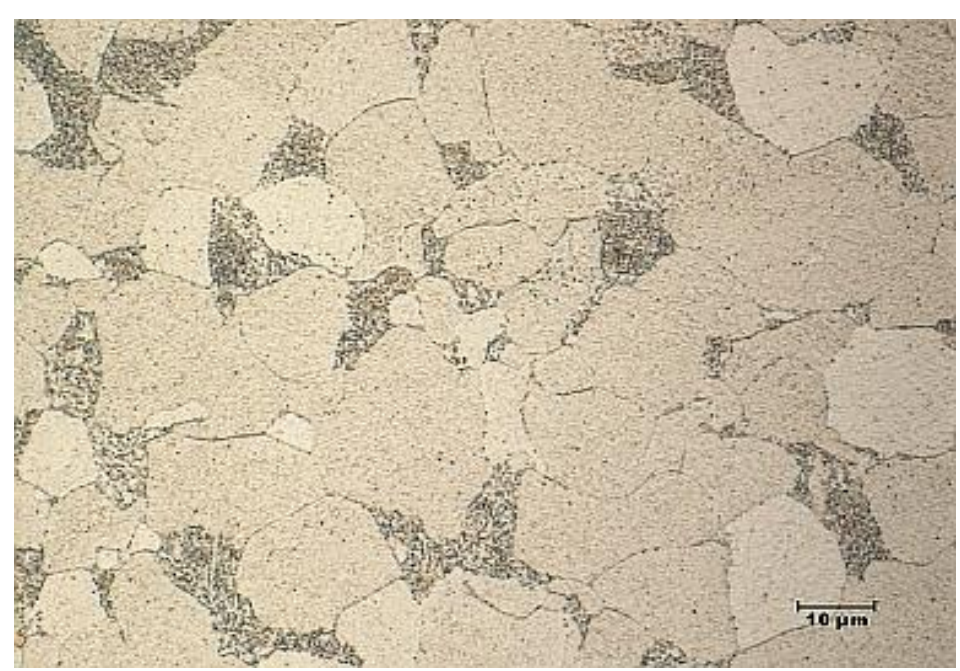

Fig. 2. Microstructure before creep tests, mag. 1000x. 


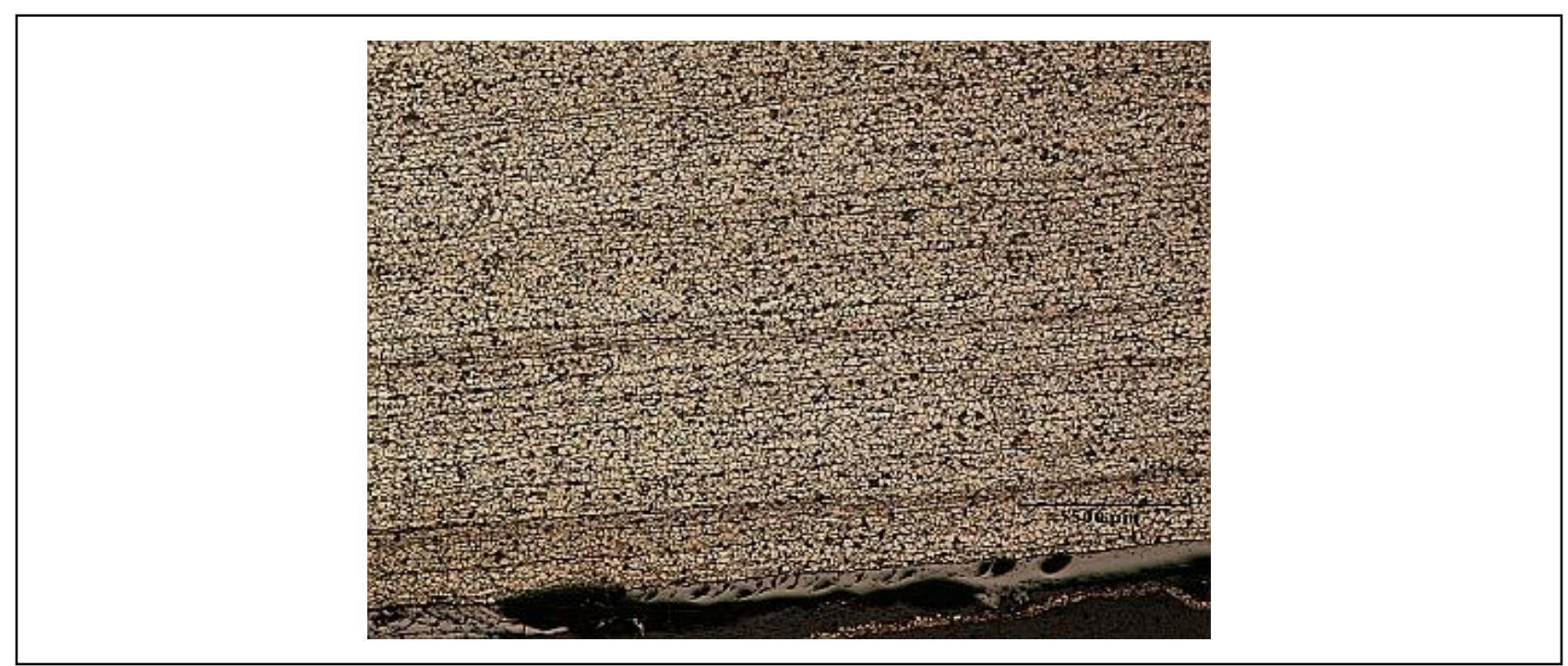

Fig. 3. Structure lines, mag. 50x.

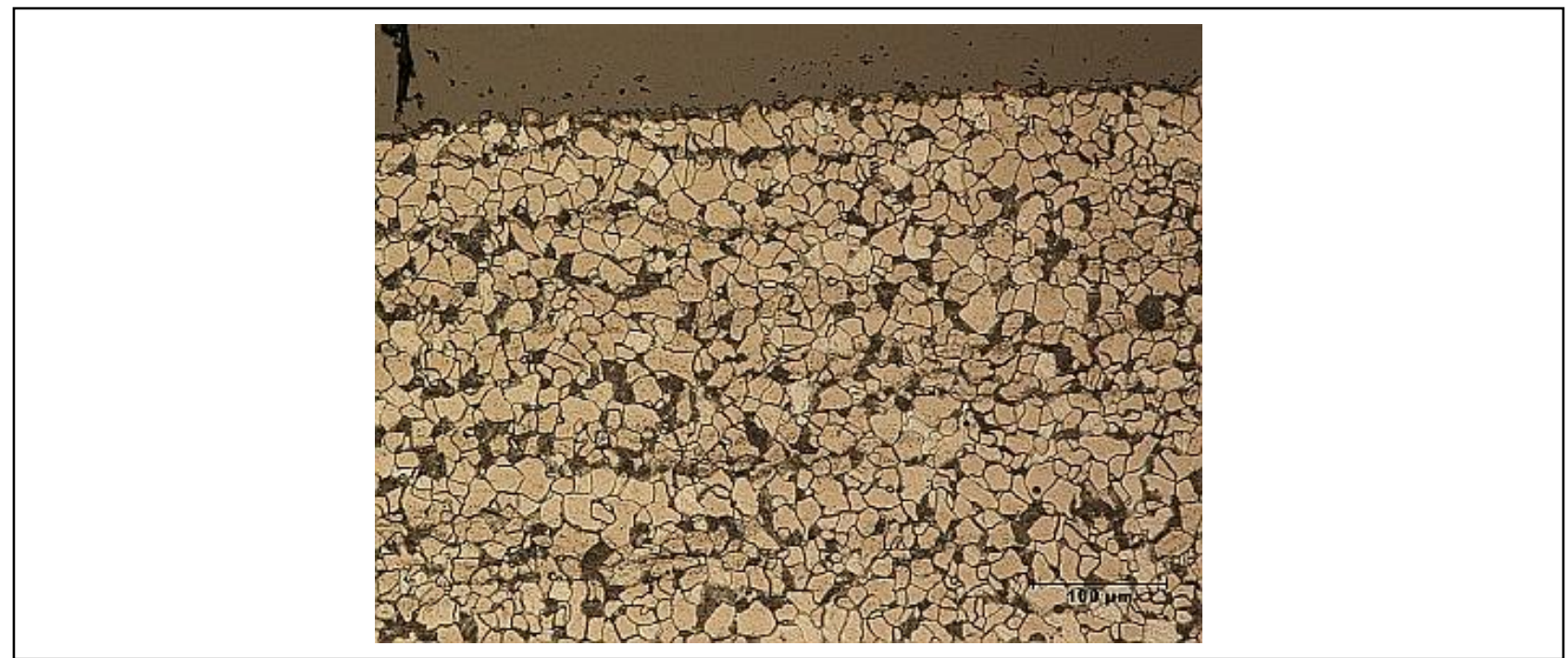

Fig. 4. Ferrite - pearlite structure, inner surface, mag. 200x.

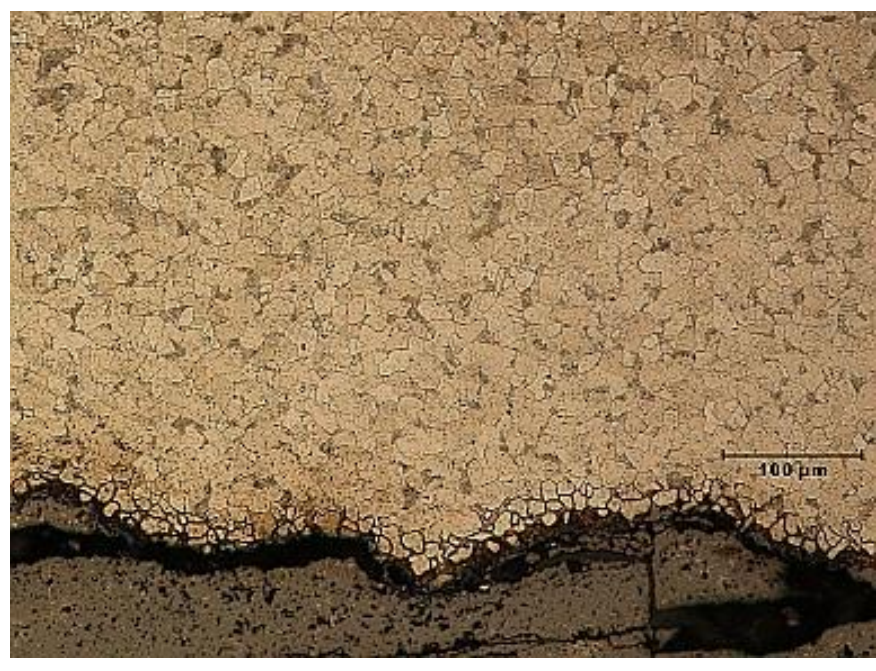

Fig. 5. Outer affected surface, mag. 200x. 
Bunda, Z.; Volak, J.; Mach, J.; Stepanek, M. \& Mentl, V.: Creep Tests and Microstr...

The microstructure of the samples before the creep testing consisted of ferrite-pearlite with uniformly distributed carbides which were spheroidized (Fig.2). The structural elements were aligned in bands as a result of cold working (Fig. 3, Fig. 4) and there were also noticeable thin decarburised layers (cca $30 \mu \mathrm{m}$ ) in areas which were close to the inner and outer surfaces of the pipes (Fig. 5). Classification of the microstructure before the creep testing is 3/IV according to the scales also mentioned in [2], [7], [8] and [9].

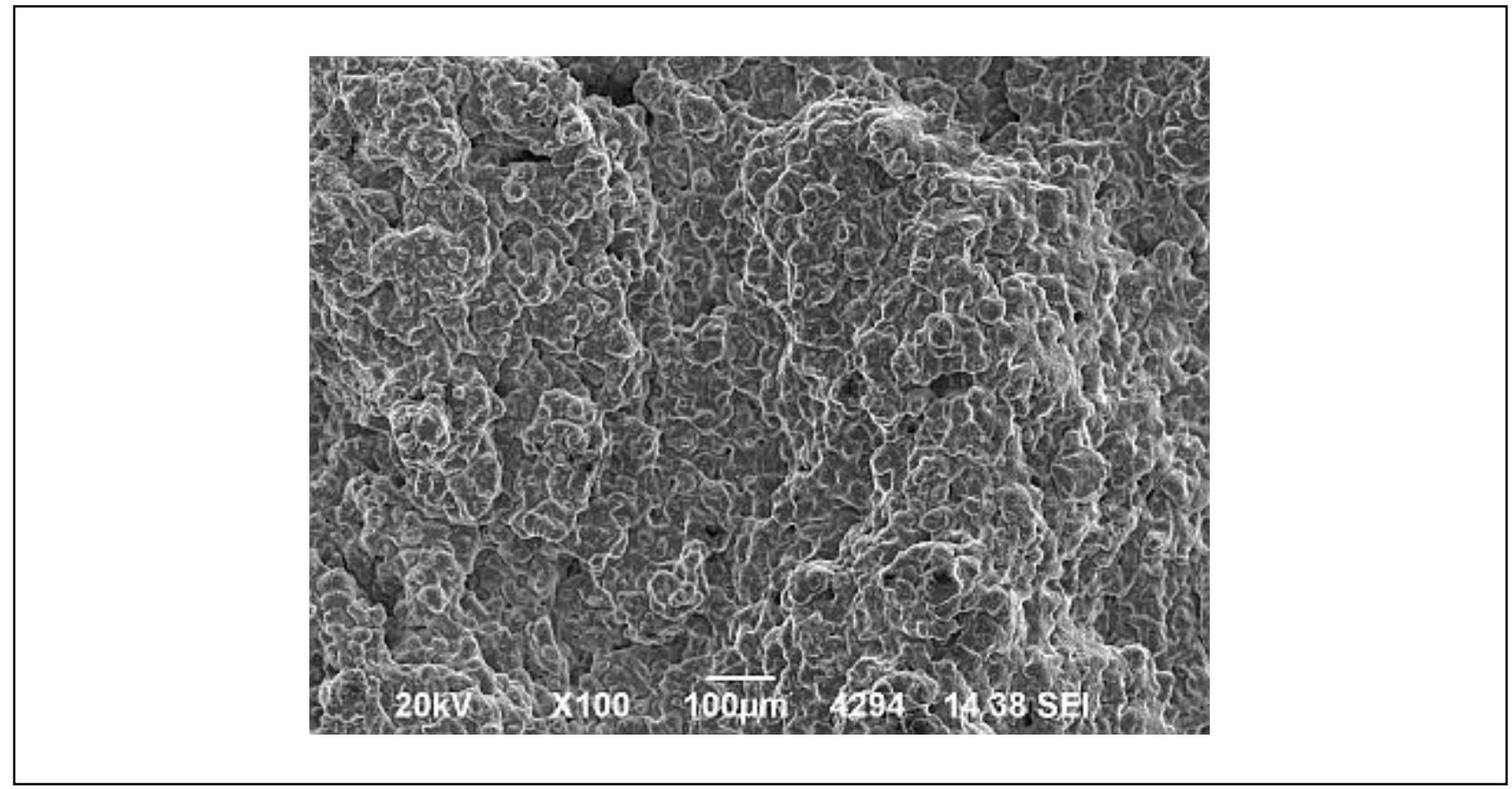

Fig. 6. Fracture area, electron microscope, mag. 100x.

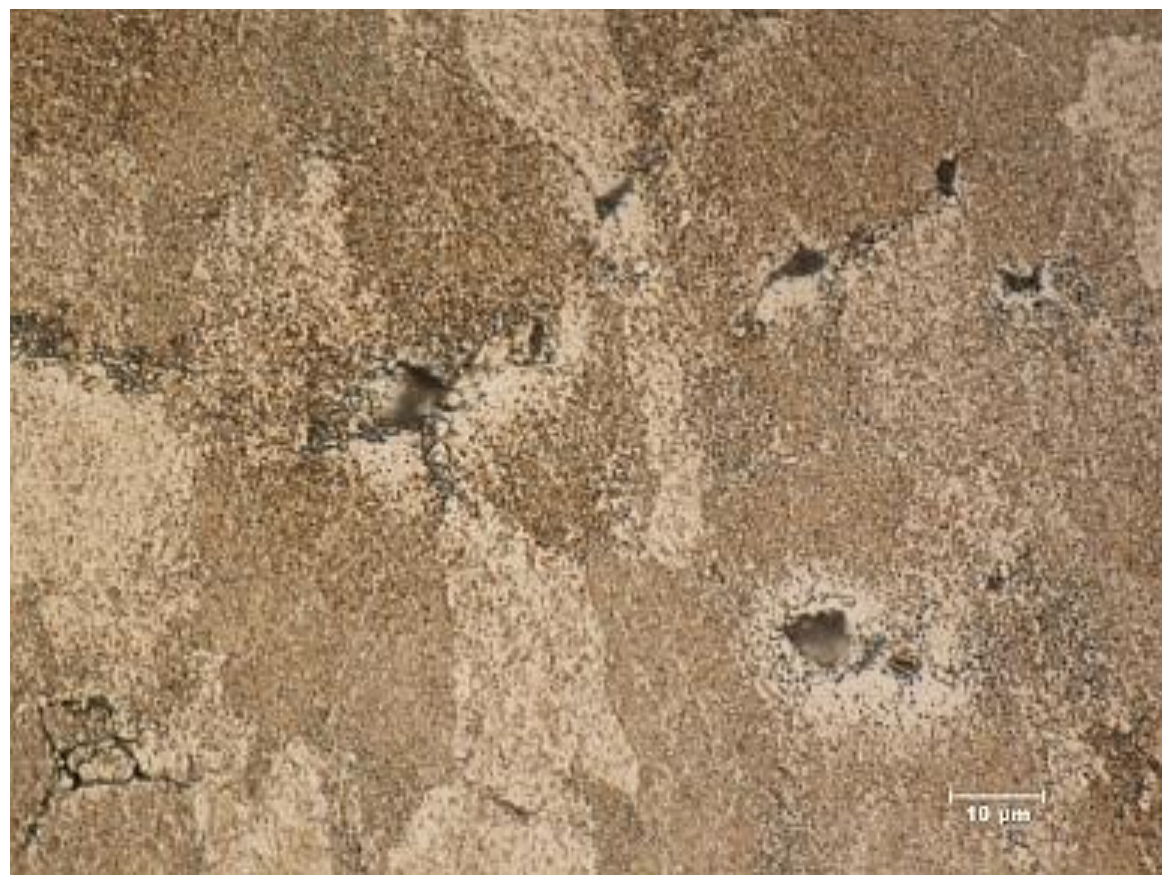

Fig. 7. Cavities, mag. 1000x 


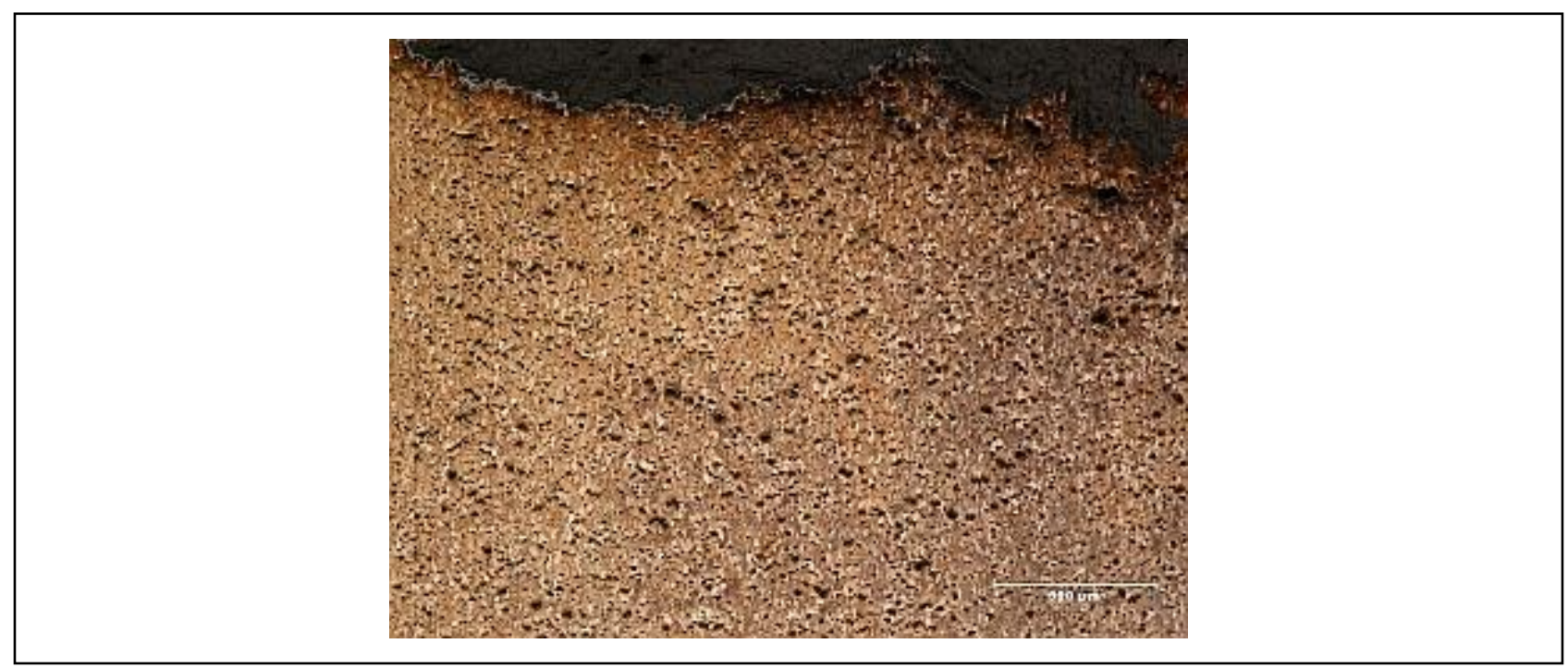

Fig. 8. Cavities close to the fracture, mag 50x

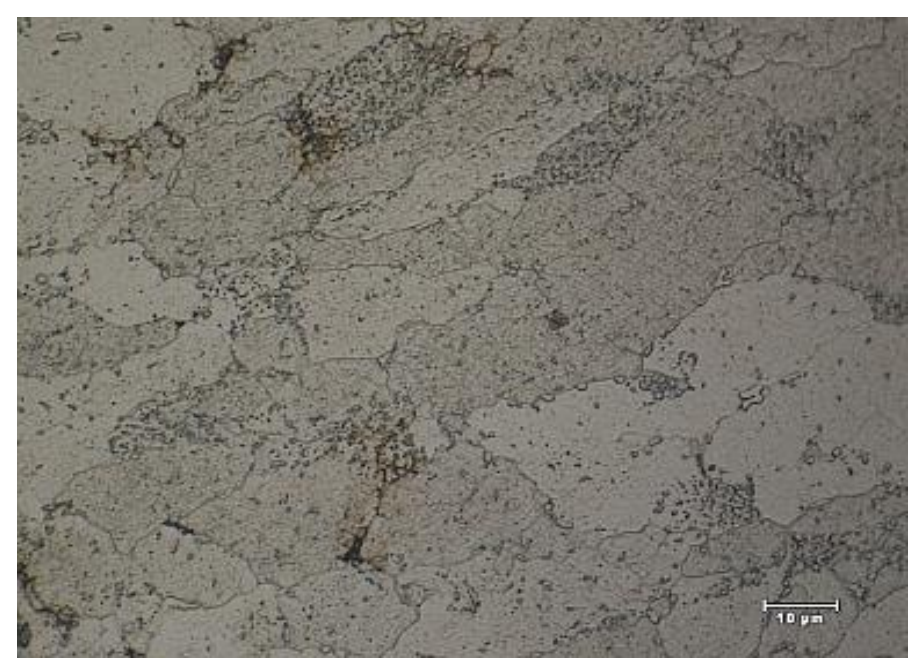

Fig. 9. Cavities and grains, mag. 1000x

The creep tests were carried out at the temperature of $580{ }^{\circ} \mathrm{C}$ and the strains from 75 $\mathrm{MPa}$ to $140 \mathrm{MPa}$. It is possible to observe a large number of cavities especially close to the intergranular fracture; these cavities coagulate and form macrocavities. The carbide particles are much coarser and are precipitated on the grain boundaries. Classification of the microstructure before the creep testing is 5/VI according to the scales also mentioned in [2], [7], [8] and [9].

\section{Conclusion}

From the comparison of the results obtained by the traditional creep tests and by the microstructure examination of the steel SA 213 - T22 it implies that it is also possible to evaluate the residual lifetime of the power plant components on the basis of the microstructure investigation. However, it is necessary to set up a database of correlations between micrographs of the materials concerned and the results obtained 
Bunda, Z.; Volak, J.; Mach, J.; Stepanek, M. \& Mentl, V.: Creep Tests and Microstr...

by the creep tests of these materials. These results can be also correlated with the hardness measurements.

The results of the creep tests of the material tested presented in this paper indicate that the residual lifetime is approximately 5 years which is in an agreement with the microstructure status classified according to two microstructure degradation standard scales. This problem deserves a comprehensive approach because of a major economic benefits can be expected due to the possibility of non-destructive replica testing.

Please read these instructions carefully. Prepare your manuscript exactly according to the instructions. That is the easiest and the most efficient way to have a good published manuscript.

(14pt)

\section{Acknowledgements}

The present contribution has been prepared under project LO1502 'Development of the Regional Technological Institute' under the auspices of the National Sustainability Programme I of the Ministry of Education of the Czech Republic aimed to support research, experimental development and innovation.

\section{References}

Skálová, J.; Kováŕík, R.; Benedikt, V. (2000). Základní zkoušky kovových materiálů, ZČU Plzeň, Plzeň

Bunda, Z.; Volak, J. Schubert, J. (2016). Remaining lifetime assessment of the boiler tube, Proceedings of Metal 2016, Brno, ISBN 978-80-87294-67-3 pp. 676-681, Tanger, Ostrava

Orfanoudakis, N., G.; Krallis, K. (2005). Selection of the optimum NDT methods for determination of steam boiler remaining life, The 8th International Conference of the Slovenian Society for Non-Destructive Testing, p. 59 - 67, Portorož, Slovenia, 2005 ASTM E 1351 Standard Practice for Production and Evaluation of Field Metallographic Replicas, 2001

DIN 54150 Non-destructive testing, impression methods for surface examination (Replica - technique, 1977)

ISO 3057 Non-destructive testing - Metallographic replica techniques of surface examination, 1998

Bunda, Z.; Volak, J.; Chvostova, E. (2013) Assessment of remaining lifetime of the boiler tube and microstructure analysis, Proceedings of Baltica 2013, ISBN 978-95138-8026-2 (URL: http://www.vtt.fi/publications/index.jsp), pp 477-483, VTT Technical Research Centre of Finland, Finland.

Volák, J.; Bunda, Z.; Kasl J. (2012). Lifetime estimation of the boiler tubes, Proceedings of Metal 2012, ISBN 978-80-87294-31-4 pp. 503-507, Tanger, Ostrava. Volak, J.; Bunda, Z. (2011). Improvement in res residual lifetime evaluation, Proceedings of Metal 2011, ISBN 978-80-87294-24-6, pp. 602-607, Tanger, Ostrava. 